\title{
DISEASE COMPLEMENTARITIES AND \\ THE EVALUATION OF PUBLIC \\ HEALTH INTERVENTIONS
}

\author{
William H. Dow \\ Jessica Holmes \\ Tomas Philipson \\ Xavier Sala-i-Martin
}

Working Paper No. 5216

\author{
NATIONAL BUREAU OF ECONOMIC RESEARCH \\ 1050 Massachusetts Avenue \\ Cambridge, MA 02138 \\ August 1995
}

We are thankful to Paul Schultz, Steen Jorgenson, José Maria Aznar, and participants at the Economic Growth Lunch at Universitat Pompeu Fabra for discussions. We also acknowledge the help of Maria Sáez Martí. Philipson acknowledges financial support from the NIH and The Rockefeller Foundation. Address all correspondence to: Xavier Sala-i-Martin, Department of Economics, Yale University, 28 Hillhouse Avenue, New Haven, CT 06520. This paper is part of NBER's research programs in Growth and Health Economics. Any opinions expressed are those of the authors and not those of the National Bureau of Economic Research.

() 1995 by William H. Dow, Jessica Holmes, Tomas Philipson, and Xavier Sala-i-Martin. All rights reserved. Short sections of text, not to exceed two paragraphs, may be quoted without explicit permission provided that full credit, including $\odot$ notice, is given to the source. 


\title{
DISEASE COMPLEMENTARITIES AND \\ THE EVALUATION OF PUBLIC \\ HEALTH INTERVENTIONS
}

\begin{abstract}
This paper provides a theoretical and empirical investigation of the positive complementarities between disease-specific policies introduced by competing risks of mortality. The incentive to invest in prevention against one cause of death depends positively on the level of survival from other causes. This means that a specific public health intervention has benefits other than the direct medical reduction in mortality: it affects the incentives to fight other diseases so the overall reduction in mortality will, in general, be larger than that predicted by the direct medical effects. We discuss evidence of these cross-disease effects by using data on neonatal tetanus vaccination through the Expanded Programme on Immunization of the World Health Organization.
\end{abstract}

William H. Dow

Department of Economics

Yale University

28 Hillhouse Avenue

New Haven, CT 06520

Tomas Philipson

Department of Economics

University of Chicago

1126 East 59th Street

Chicago, IL 60637
Jessica Holmes

Department of Economics

Yale University

28 Hillhouse Avenue

New Haven, CT 06520

Xavier Sala-i-Martin

Department of Economics

Yale University

28 Hillhouse Avenue

New Haven, CT 06520

and NBER 


\section{Introduction}

Reliability theory provides some insight to engineers who are interested in evaluating how the lifetimes of different components of a machine affect the survival and durability of the whole device. Engineers use information about the overall structure and interdependence among the components to estimate the expected life length and durability of the system. For example, they might make use of the fact that for a particular machine, the weakest link determines the overall survival of the system and thus life length is calculated as a function of the reliability of the weakest component. Human life-extension may be likened to engineering life-extension of machines. One need only consider the human body as the machine, the body parts analogous to the machine components and health care as the costly repair and maintenance of the system. Indeed, in most developed countries, the old-aged, whose medical needs account for the largest fraction of health expenditures, are almost full-time life-extension workers.

There is one major difference between human and machine reliability theory that must be emphasized and will in fact be an important aspect of this paper. With regard to human life extension, there may be important spillovers across components as the reduction in the probability of death from one "failed component" affects the incentives to invest in the prevention of alternative life-threatening "component failures" (or diseases). Consider, for example, the Expanded Program on Immunizations (EPI) of the World Health Organization. This major public health program immunizes children against diseases estimated to contribute significantly to the high child mortality rates in many developing countries. The effect on child mortality of this medical intervention is likely to be dramatic on many grounds. Beyond the first direct medical effects of the vaccinations on the specific diseases, we want to stress the additional indirect effect that such a program may have on people's behavior towards other health hazards. For example, mothers whose children are more likely to survive neonatal tetanus as a result of an immunization campaign may have an incentive to increase other health inputs such as nutrition, now that such inputs are less likely to be wasted on children who otherwise would likely have died.

Another example might be found in a cure for certain types of lung cancer. The discovery of such cure is likely to have several effects. The first one is the direct decrease in the number of deaths from lung cancer. The second, 
indirect, effect is the decrease in the number of deaths from other causes in people weakened by lung cancer. For example, people with lung cancer are more susceptible to death from pneumonia and are also less likely to receive heart bypasses because doctors think that these inputs will be "wasted" on someone about to die anyway. An additional indirect effect is behavioral: if lung cancer is no longer a health threat, people may start smoking again or they may start worrying about prostate cancer or heart diseases.

A third example involves the behavior of young people in American inner cities. Urban centers in the United States are often characterized by significant mortality from both violence and AIDS. Consider the effect of a public intervention that decreases violent crime significantly. This would first lead to a direct increase in life expectancy for inner city kids no longer susceptible to life threatening violent acts. In addition, in response to the higher likelihood of survival, inner city kids may react by changing behavior and protecting themselves against HIV, the next expected cause of death, by having protected sex or not sharing drug needles.

Given that most of the high expenditure programs of international, national, and subnational governments involve disease-specific interventions (like, for example, measles vaccination programs, HIV education programs, mammogram screening programs, and cancer research) it seems natural that the proper evaluation of the success of such programs take into account the spillovers we just described. Typically, however, the success or failure of these programs is determined by evaluating exclusively their impact on the targeted disease. If, as we argue in this paper, these disease-specific policies are likely to have large cross-effects on the mortality and morbidity of other diseases, then in order to understand the effects of these programs, and hence to evaluate them better, one must better understand these cross-cause effects.

The objective of this paper is to analyze the behavioral interactions between disease-specific interventions and other contemporaneous diseases both theoretically and empirically. The paper is organized as follows. Section 2 studies the valuation of disease-specific policies when mortality reductions are exogenous. Special emphasis is paid to the case of competing mortality risks which corresponds to the Leontief production of lifetime survival. This production function for overall lifelength implies a complementarity between competing mortality risks: the marginal benefit of avoiding one disease is increasing in the degree to which other diseases are dependent on the characteristics of the other diseases present. In particular, we study the conditions 
under which exogenous disease-specific interventions can be evaluated by their relative impact on mortality and morbidity only, without reliance on preference information. The complementarity implied by the Leontief competing risk model has counter-intuitive effects that have not received sufficient attention in theoretical as well as practical analyses of disease-specific interventions.

Section 3 discusses the effects of disease-specific policies on mortality when mortality is taken to be endogenous. Two interventions are considered. The first one is a reduction in the price of a quality-adjusted health input. The second is an exogenous improvement in the medical environment through a medical innovation. We study how the complementarity between causes of death under competing risks affects the way in which individuals invest in health inputs, other than those directly influenced by the intervention. We investigate the behavioral spillovers discussed above and show why competing risks imply that cause specific investments are complementary. Furthermore, we show that overall survival effects of disease specific interventions are therefore understated if such complementary effects are ignored.

Section 4 presents empirical evidence suggesting that behavioral responses in cross-inputs may be significant. We analyze the Expanded Program on Immunization: a major public health program which allocates $\$ 1.5$ billion annually for child vaccinations in developing countries and is administrated by The World Health Organization. Using the 1992 Zambian Demographic and Health Survey, we find that the effects of immunization against neonatal tetanus are considerably larger than can be accounted for through direct medical effects. Paraphrasing the title of the paper: when a "tetanus" program is introduced, pregnant women are likely to take better care of themselves ("aerobics") so that "mortality" rates change more than one would have thought by looking at the direct survival effects of tetanus. Even after controlling for heterogeneity with sibling fixed effects estimation, it appears that the complementary effect remains. 


\section{Evaluation of Disease-Specific Interventi- ons Under Exogenous Mortality}

This section analyzes the valuation of effects of lifetime extension when there are multiple causes of death in the case of an exogenous lifetime. By "exogenous lifetime" (a common, although not always explicit assumption used in the value of life-extension literature ${ }^{2}$ ) we mean that the observed lifetime is not the result of some optimal choice. We stress the disease complementarities that exist in evaluating disease-specific programs, particularly so under competing diseases. An important aspect of our discussion is that the relative evaluation of disease-specific programs may be done by simply referring to knowledge of survival $S$ without reference to harder to estimate preference parameters. This is important because it allows for the incorporation of the many empirical epidemiological estimates of multiple cause survival functions ${ }^{3} S$ into an interpretable utility-based evaluation framework.

\subsection{Deterministic Case}

Let us start by making an analogy between machines and bodies: a body is a compilation of parts in the same way that a machine is the sum of its components. The lifetime of each of the components (occurrence of a particular disease) determines the lifetime of the whole machine (death). Let $t_{i}$ be the disease $i$ lifetime (defined as the moment in which disease $i$ appears) and let $t=\left(t_{1}, . ., t_{n}\right)$ be the vector of deterministic disease lifetimes. Let $T=f(t)$ denote the total lifetime of the individual.

The value function of lifetime, $\mathrm{T}$, and wealth, $\mathrm{W}$ is denoted by $V(T, W)$ and given by

\footnotetext{
${ }^{2}$ See e.g. Viscusi (1992), Rosen (1994), or Kenkel et al (1994)

${ }^{3}$ The literature on this is vast. See, for example, the reviews in Manton and Stallard (1987).

${ }^{4}$ This specification ignores the, no doubt important, effects of health on productivity and happiness in order to concentrate on the effects of health on life extension. It is true, however, that some diseases reduce people's ability to collect labor income without affecting the overall life length (for example, the loss of an eye or a leg reduces a person's productivity but it does not affect his life expectancy). Similarly, some diseases which are not life-threatening and do not affect people's productivity, are "annoying" enough so that the overall level of happiness and utility is affected without any effects on wealth,
} 


$$
\begin{gathered}
V(T, W)=\operatorname{Max} \int_{v=0}^{T} U(c(v)) e^{-r v} d v \\
s t \int_{v=0}^{T} c(v) e^{-r v} d v \leq W
\end{gathered}
$$

The value of one additional year of life in terms of utility is given by $d V / d T$. Intuitively, the value of an additional year of life will be affected by three major components: First, holding constant lifetime wealth, $W$ and the consumption path, $c$, a marginal increase in $\mathrm{T}$ will add more terms to the utility function. The contribution of this effect to utility will therefore be positive. Second, holding the consumption path and the "number" of additive terms in $\mathrm{V}()$, a marginal increase in $\mathrm{T}$ may increase the overall lifetime wealth. This will be true if the additional time can be used for work (in other words, if the additional lifetime does not come after the person has already retired). This effect is also a positive contribution to utility (except for retired people when there is no PAYG social security, for whom an additional year of life would entail no extra lifetime income.) Finally, holding constant lifetime wealth and the number of additive terms in $\mathrm{V}()$, additional lifetime reduces the amount of consumption we can enjoy each period. This third component will tend to introduce a negative effect on the marginal utility of lifetime.

The marginal utility of additional lifetime in terms of goods is given by the ratio of the marginal utility of additional lifetime and the marginal utility of wealth. This is, of course, the marginal rate of substitution between lifelength and wealth: $M R S \equiv(d V / d T) /(d V / d W)$.

The marginal contribution of a reduction of a specific disease to overall utility will come through its contribution to the change in overall lifetime. Suppose that a particular vector of disease lifetimes, $t=\left(t_{1}, . ., t_{n}\right)$, is associated with a specific lifelength $\mathrm{T}$ through the function $T=f(t)$. The value function associated with the vector $t$ is denoted by $\mathrm{Z}(\mathrm{t}, \mathrm{W})$ and is defined as

$$
Z(t, W) \equiv V(f(t), w) .
$$

As an example, consider the case of two diseases which appear at times $t_{1}$ and $t_{2}$. Imagine further that these two diseases are fatal. The length of life associated with these two diseases is the Leontief lifetime function

$$
T=f\left(t_{1}, t_{2}\right)=\min \left\{t_{1}, t_{2}\right\},
$$

consumption or life length. Examples of these could be dandruff or skin rashes. 
which corresponds to a deterministic version of the so called competing risk model. In this case the induced value function is given by $Z\left(t_{1}, t_{2}, w\right)=$ $V\left(t_{1}, w\right)$ if $t_{1} \leq t_{2}$ and $Z\left(t_{1}, t_{2}, w\right)=V\left(t_{2}, w\right)$ if $t_{2} \leq t_{1}$

An important implication is that the value of prolonging the onset of a fatal disease may be zero if it is not the most immediate. In other words, the marginal value of an increase in the time of the onset of a disease satisfies

$$
\begin{aligned}
d Z / d t_{k} & =(d V / d T)\left(d f / d t_{k}\right) \geq 0, \\
d^{2} Z / d t_{k} d t_{k^{\prime}} & =(d V / d T)\left(d^{2} f / d t_{k} d t_{k^{\prime}}\right) \geq 0
\end{aligned}
$$

Intuitively, the contribution of postponing the onset of disease $k$ to utility is the marginal effect of this postponement to lifetime (given by $d f / d t_{k}$ ), times the marginal value of additional lifelength (given by $d V / d T$.) . The corresponding value in terms of wealth is given by

$$
\left(d Z / d t_{k}\right) /(d Z / d W)=\left(d f / d t_{k}\right)[(d V / d T) /(d V / d W)]=\left(d f / d t_{k}\right) * M R S \geq 0
$$

$$
\left(d^{2} Z / d t_{k} d t_{k^{\prime}}\right) /(d Z / d W)=\left(d^{2} f / d t_{k} d t_{k^{\prime}}\right) * M R S \geq 0
$$

Note that, when $f(t)$ takes the Leontief form, this marginal valuation is zero for components that are not the shortest in lifetime. That is, $t_{k}>$ $\min \left\{t_{1}, . ., t_{n}\right\}$ implies $\left(d Z / d t_{k}\right) /(d Z / d W)=0$.

The relationships above hold regardless of the indirect utility function $V(T, W)$ as long as it is increasing in both arguments. As an illustration, consider the case of the pure permanent income hypothesis. For a single cause of death Arthur(1981) and Rosen (1988, 1993) show that the value function over duration of life and wealth in this case can be written as

$$
V(T, W)=B[T] u(W / B[T])
$$

where $B[T] \equiv \int_{t=0}^{T} \exp (-r t) d t$ is the value of an annuity in $[0, T]$. A particular case of this expression is when there is no discounting (interest and discount rates are zero so that the consumption profile is flat). If you live for $T$ years and divide your wealth equally across these years then per period consumption will be $W / T$, the per period utility $u(W / T)$, and the corresponding lifetime utility for all years $T u(W / T)$. The formula above is the analog lifetime utility for the case when the interest rate is such that $B[T]$ is different from $T$. The value function $V(T, W)=T u(W / T)$ can be used to 
see the various effects described above. The first term $T$ reflects the positive contribution of additional lifetime to utility which results from the addition of more "terms" to our utility function. The second contribution of $\mathrm{T}$ to utility comes from a reduction of consumption through the term W/T: given $W$, additional years of life require lower consumption each period and, therefore, a lower utility. In this case, the marginal value of a particular disease-length $t_{k}$ satisfies

$$
d Z / d t_{k}=\left[d f / d t_{k}\right][d V / d T]=\left[d f / d t_{k}\right]\left[u()+T u^{\prime}()\left(-W / T^{2}\right)\right]
$$

The two terms with different signs inside the second bracket reflect the offsetting effects we just discussed. If, furthermore, a larger $\mathrm{T}$ is associated with a larger lifetime wealth (as it would be in the case for people who get additional years of working life), then $\mathrm{W}$ would be increasing in $\mathrm{T}$. This would represent an additional (positive) effect of $T$ to $V$. However, this term would be zero if (as we assume in the formula) the additional years of life do not entail any additional earnings (so that $\mathrm{W}$ is independent of $\mathrm{T}$ ).

This is the simplest deterministic illustration of the complementarity in willingness to pay for cause specific interventions under competing risks. Under competing risk (that is, under the Leontief production function) we see two interesting properties. First, the marginal contribution of specific components to utility are zero if they are not the shortest in lifetime. The second important property is that one cause of death interacts with another in the sense that the willingness to pay to the onset of one is a positive function of the time to the other.

\subsection{Stochastic Case}

We can now generalize the deterministic case by introducing stochastic components to lifetimes. Let $S(t)$ be the overall lifetime survival function interpreted as the fraction of individuals surviving past age $t$. It depends on the survival functions of each of the causes of death $S_{i}\left(t ; x, \theta_{i}\right)$, where $\theta_{i}$ are parameters that determine disease-specific survivals:

$$
S(t ; x, \theta)=f\left(S_{1}\left(t ; x, \theta_{1}\right), . ., S_{n}\left(t ; x, \theta_{n}\right)\right)
$$

Note that $f:[0,1]^{n} \rightarrow[0,1]$ determines the probability of overall survival, given component survivals and $\theta=\left(\theta_{1}, . ., \theta_{n}\right)$. The term $\mathrm{x}$ represents a vector 
of disease-specific investments (which will be relevant in the next section.) The equation $S=f()$ corresponds to $T=f()$ in the deterministic case.

Following the deterministic analog of the previous section, we define the induced value function as

$$
Z(\theta, W) \equiv V(S(t ; x, \theta), W) \equiv V\left(f\left(S_{1}\left(t ; x, \theta_{1}\right), \ldots, S_{n}\left(t ; x, \theta_{n}\right)\right), W\right) .
$$

For example, for independent competing risks, $f$ is given by the product of its arguments. The stochastic value function reduces to the deterministic one when all individuals are the same and the survivals are Dirach measures. Using the permanent income hypothesis, Rosen (1994) shows that the value of a given survival function and wealth pair is

$$
V(S, W)=B[S] u(W / B[S])
$$

where $B[S] \equiv \prod S(t) \exp (-r t) d t$. It is the direct stochastic analog to the earlier deterministic formula $V(T, W)=B[T] u(W / B[T])$ which results for the special case of the atom survival $S(t)=1$ if $t \leq T$ and $S(t)=0$ if $t \geq T$ in which case $B[S]=B[T]$. The term $B[S]$ can be interpreted as the value of an annuity given the probability of survival $S$. It may also be interpreted as the expected overall lifetime of two independent competing risks, one with exponential lifetime and failure rate $r$, corresponding to discounting due to time preference, and another risk with component survival S. The induced value function satisfies

$$
Z\left(S_{1}, . ., S_{n}, x, W\right)=B[f, x] u(W / B[f, x])
$$

where

$$
B[f, x] \equiv B\left[f\left(S_{1}(t ; x), . ., S_{n}(t ; x)\right] .\right.
$$

The term $B[f, x]$ reduces to the deterministic factor $B[T]$ if all $S_{k}$ have one atom at $T$.

When there are competing independent risks, then $f=\prod S_{k}$ and the same type of disease complementarity affects the marginal value of improving the survival for a particular disease

$$
\frac{d S(t)}{d \theta_{k}}=d S_{k}(t) / d \theta_{k} \prod_{k^{\prime} \neq k} S_{k^{\prime}}(t)
$$


In other words, the marginal benefit in extending the overall survivals is increasing in the level of the survival in terms of other causes of death. This result parallels the one found in the previous section for the deterministic case.

\section{Evaluation of Disease-Specific Interventi- ons Under Endogenous Mortality}

In the previous section we ignored the behavioral responses to health policies because we wanted to focus on the technological aspects on valuation of life extension under competing risks. ${ }^{5}$. Consider the case of $K$ diseases, and let disease specific investments be priced at $p=\left(p_{1}, p_{2}, . ., p_{K}\right)$ with $x(p)=\left(x_{1}(p), x_{2}(p), . . x_{K}(p)\right)$ denoting the demand for health inputs at the prices. Under competing risks, these investments lead to the overall probability of survival $S(t \mid x(p))=\prod S_{i}\left(t \mid x_{i}(p)\right)$ Generally the effect of a price change related to one specific disease is then

$$
\frac{d S(t \mid x(p))}{d p_{k}}=\sum_{i=1}^{K} \frac{d S_{i}\left(t \mid x_{i}(p)\right)}{d x_{i}} \frac{d x_{i}}{d p_{k}}\left(\prod_{j \neq i} S_{j}\right)
$$

In particular, when disease specific health investments are complements in the sense that cross-price effects are negative, $d x_{i} / d p_{k} \leq 0$, the overall survival dominates the disease specific effect

$$
\frac{d S(t \mid x(p))}{d p_{k}} \leq \frac{d S_{k}\left(t \mid x_{k}(p)\right)}{d x_{k}} \frac{d x_{k}}{d p_{k}}\left(\prod_{j \neq k} S_{j}\right)
$$

In other words, when health inputs are complementary, which they often will be under competing risks, conventional analysis understates the overall survival effects.

To illustrate the complementary effects of the health input demand function we under competing risk, consider a simple two period model which generalizes to several periods directly. We assume that individuals live one period with probability one and that they survive with probability $S(x(p))$

\footnotetext{
${ }^{5}$ Optimal investment in life- extension displays similarities to recent models of optimal discounting (see Becker and Mulligian (1994).
} 
under input demand $x(p)$. The two period survival version of the competing risk model analyzed in previous sections is

$$
S \equiv \prod_{i=1}^{K} S_{i}\left(x_{i}\right)
$$

where we assume that disease specific survival rise with its investment at a decreasing rate $S_{i}^{\prime} \geq 0$ and $S_{i}^{\prime \prime} \leq 0$. The overall expenditure in health in terms of good $x_{1}$, which we call $H$, is equal to the value of all disease-specific investments:

$$
H=\sum_{i=1}^{n}\left(p_{i} / p_{1}\right) x_{i}
$$

Individuals also choose to consume non-health goods in both periods denoted $C_{1}$ and $C_{2}$ with the price of consumption being normalized to unity. Survivors work in both periods and receive wages $W_{1}$ and $W_{2}$, respectively. It is optimal for agents to purchase annuities when they are young. The return to annuities provides an additional source of income (if the consumer is alive) in the second period. Let the annuity purchased in the first period be $b_{1}$. At the beginning of period 2, the principal plus interest of the annuities market is distributed equally among the survivors. Each of them, therefore, receives $(1-S)\left[b_{1}(1+r)\right] / S$ (note that this depends on the aggregate probability of survival, $S$, and on the market rate of return, $r$.) Note further that, even though $S$ is determined by the aggregate of all the individual survival rates (each of which depends on individual choices), individuals take the aggregate survival probability (and therefore the aggregate rate of return from the annuities market) to be exogenous. That is, they assume that their behavior does not influence the aggregate survival level $S$. Since all consumers are identical and optimally behave in the same way, the following condition is true:

$$
S(H) \equiv S
$$

Each consumer then solves the following optimization problem:

$$
\max _{C_{1}, C_{2}, x_{i}} U\left(C_{1}\right)+S \frac{U\left(C_{2}\right)}{1+\rho}+[1-S] \frac{U^{d}}{1+\rho}
$$


Subject to

$$
W_{1}=b_{1}+C_{1}+\sum_{i=1}^{n} p_{i} x_{i}
$$

and

$$
W_{2}+b_{1}(1+r)+\frac{(1-S) b_{1}(1+r)}{S}=C_{2}
$$

where $\rho$ is the rate of time preference and $U^{d}$ is the utility of being dead 6. This leads to the intertemporal budget constraint:

$$
C_{1}+C_{2} \frac{S}{1+r}+\sum_{i=1}^{n} p_{i} x_{i}=W_{1}+W_{2} \frac{S}{1+r}
$$

We solve the above problem in two steps. First, holding the level of health expenditure constant, one can analyze the optimal allocation of resources among disease-specific preventions. We will call this the static problem. Second, ignoring the distribution of resources within health investment, the optimal allocation of income between consumption and health investment. We refer to this as the dynamic problem.

Static Problem In the first step, consumers maximize their total survival probability by investing in disease-specific preventions, subject to an exogenously determined level of health spending as in

$$
\operatorname{Max}_{x} S=\prod_{i=1}^{K} S_{i}\left(x_{i}\right)
$$

Subject to

$$
H=x_{1}+\left(p_{2} / p_{1}\right) x_{2}+\cdots+\left(p_{n} / p_{1}\right) x_{n}
$$

where $H$ is the overall spending in health defined above. The solution of this simple maximization problem yields that the cross price effect of the demand for health inputs, $d x_{/} d p_{j}$, may be negative or positive depending on

\footnotetext{
${ }^{6}$ In order to avoid suicide and other corner solutions which would lead to the desire to invest negative amounts of $x_{i}$, we assume that the utility of being alive in the second period is larger than the utility of being dead; Hence, we cannot assume, as most OLG models usually do, that $U^{d}$ is zero in general, unless we make sure that the utility of being alive is positive.
} 
how big the income effect is relative to the substitution effect. Consider a proportional decrease in the prices of all health goods leaving the relative prices $p_{i} / p_{1}$ unchanged. Since the allocation of $H$ across the different health inputs depends solely on these relative prices $p$ and on the level of $H$ (which remains unchanged), the demand for each of the components $x_{i}$ does not change. Since the price of health goods changes relative to consumption goods, there will be a change in the allocation of wealth between these two types of goods. And this is what we analyze with the dynamic model. The key point is that the demand for each of the individual health goods $x_{i}$ depends upon the relative prices and upon the level of $H$, but it is independent on the overall price of health in terms of consumption goods.

Dynamic Problem We define the overall survival as a function of total health expenditures $S(H) \equiv \prod S_{i}\left(x_{i}(H, p)\right)$ where $x_{i}(H, p)$ is the health input demand given total expenditure and prices. This yields that the consumption survival choice solves

$$
\operatorname{Max}_{C_{1}, C_{2}, H} U\left(C_{1}\right)+S(H) \frac{U\left(C_{2}\right)}{1+\rho}+[1-S(H)] \frac{U^{d}}{1+\rho}
$$

Subject to

$$
C_{1}+C_{2} \frac{S(H)}{1+r}+p_{1} H=W_{1}+W_{2} \frac{S(H)}{1+r} .
$$

Note that the expenditure level $H$ in the budget constraint has been multiplied by $p_{1}$ because $H$ was expressed in terms of good $x_{1}$ and the budget constraint is written in terms of consumption good $C_{1}$. The above constraint implies that positive shocks to aggregate survival probability (increases in $A$ ) leave surviving consumers poorer. As more people survive into the second period, returns from the annuities market fall since less wealth must be distributed among more individuals. It follows that consumers $\operatorname{discount} C_{2}$ and $W_{2}$ at a higher rate.

We assume that the utility function has a constant intertemporal elasticity of substitution with parameter $\theta$

$$
U(C)=\frac{C^{1-\theta}}{1-\theta} \quad 0<\theta<1,
$$


The assumption $0<\theta<1$ is imposed to ensure that the utility achieved if alive in the second period is positive. Thus, we can set the utility of being dead equal to zero and still be sure that individuals will be willing to invest positive amounts of resources in health.

The first order conditions with respect to both consumption and health follow immediately from the maximization of 25 with respect to 26 .

The first order condition (FOC) for first period consumption is the familiar one: the marginal utility of consumption is equal to the shadow price of wealth:

$$
C_{1}^{*-\theta}=\lambda
$$

Similarly, the FOC for second period consumption imposes the usual requirement that the marginal utility of consumption, discounted by the interest rate and consumer's time preference, must equal the marginal utility of wealth, $\lambda$ :

$$
C_{2}^{*-\theta}=\frac{1+\rho}{1+r} \lambda
$$

Finally, the FOC with respect to health, $H$, implies that the marginal benefit of additional survival must be equal to the marginal cost of purchasing such additional survival:

$$
\frac{C_{2}^{*(1-\theta)}}{1-\theta} \frac{S^{\prime}\left(H^{*}\right)}{(1+\rho)}=\lambda p_{1}
$$

Substitution of 28 into 29, leads to the familiar Euler equation.

$$
\frac{C_{2}^{*}}{C_{1}^{*}}=\left(\frac{1+r}{1+\rho}\right)^{\frac{1}{6}}
$$

Consumption growth is a positive function of the difference between the interest rate and the discount rate and a negative function of $\theta$. The interesting point is that the optimal substitution between $C_{1}$ and $C_{2}$ is independent of both $A$ and $H$. It follows that changes in overall health level or shocks to survival probability affect the relative distribution of consumption across periods. Substitution of 29 into 30 yields the optimal value for second period consumption: 


$$
C_{2}^{*}=\frac{p_{1}(1+r)(1-\theta)}{S^{\prime}\left(H^{*}\right)}
$$

Plugging 32 into 31 provides the optimal level of initial consumption:

$$
C_{1}^{*}=\left(\frac{1+\rho}{1+r}\right)^{\frac{1}{\theta}} \frac{p_{1}(1+r)(1-\theta)}{S^{\prime}\left(H^{*}\right)}
$$

Finally, we can use 32 and 33 along with the budget constraint 26 to get the optimal level of health investment, $H^{*}$ :

$$
W_{1}+W_{2} \frac{S}{1+r}-p_{1} H^{*}=\left(\frac{1+\rho}{1+r}\right)^{\frac{1}{\theta}} \frac{p_{1}(1+r)(1-\theta)}{S^{\prime}\left(H^{*}\right)}+\frac{S}{1+r} \frac{p_{1}(1+r)(1-\theta)}{S^{\prime}\left(H^{*}\right)}
$$

For a given level of $H$, consider a reduction of the price of health investment, $p_{1}$. Remember that $p_{1}$ is the price that transforms total health expenditure (expressed in units of good $x_{1}$ ) into the consumption good. The income effect from a decrease in $p_{1}$ implies an increase in the left side of equation 34: as health investment becomes less costly, it frees up resources leading to an expansion of the consumer's budget set. This income effect predicts that consumption in both periods should rise along with higher health investments. The substitution effect induced by the lower cost of health also leads to an increase in health investment as resources are shifted away from both first and second period consumption. The positive effect on health investment comes from a reduction of the right side of 34 . It is clear that any health policy that reduces the price of health investment will unambiguously increase the individuals' optimal level of health investment. The dynamic model therefore predicts that the implementation of policies such as free immunizations will lead to a reaction by individuals characterized by higher equilibrium health investments. The effect of cheaper health investments on the optimal period-specific consumption of non-health goods is less unambiguous since income and substitution effects work in opposite directions.

We are now in a position to combine the static and dynamic effects of decreases in the price of disease-specific preventions. We found that, holding constant $H$, a reduction in $p_{1}$ will lead to a change in the relative price of goods $x_{1}$ and $x_{2}$. The demand for $x_{1}$ will unambiguously rise and the demand 
for $x_{2}$ will increase or decrease depending on the relative sizes of the wealth and substitution effects. We then found that the reduction in $p_{1}$ makes the price of $H$ lower relative to consumption. This will trigger an increase in the demand for $H$ and, as a result, an increase in the demand for $x_{1}$ and $x_{2}$. The main message is that the overall effect of policies that reduce the costs of fighting specific diseases will likely increase the investment in protection against alternative diseases.

\section{Empirical Evidence of Cross-Input Re- sponses to a Disease-Specific Intervention}

This section provides some empirical support for the view that the introduction of disease specific health programs leads people to alter investments in health inputs, including those inputs not directly or obviously related to the specific intervention. The intervention analyzed in this section is the Expanded Program on Immunizations (EPI). This program, primarily relied upon during the 1980's, initiated a tremendous increase in child vaccination rates in many developing countries, often increasing rates from less than $20 \%$ to over $80 \%$ for measles, DPT, BCG, polio, and neo-natal tetanus (see e.g. The World Bank (1993)). We use the 1992 Demographic and Health Survey (DHS) to analyze the existence of indirect or spillover effects of the EPI in Zambia.

We first show that tetanus vaccination appears to affect mortality past the neonatal stage. Furthermore we show that it affects birthweight, a phenomenon for which there could be no direct medical pathway. This provides some support for the hypothesis that when the EPI package is available to a mother's children (measured by the availability of the tetanus vaccine during a prenatal visit) the mother is willing to increase her investment in other unobserved dimensions of health. These increases in other health inputs improve birthweight as well as the overall health and life expectancy of the child.

\subsection{The Data and The Implementation of EPI}

The Zambia DHS is a nationwide random household survey covering 7060 women. Retrospective information was collected for each woman in the house- 
hold regarding births in the previous 5 years (since 1987). This included data on prenatal care, birthweight, vaccinations, and the age at which deceased children had died. Summary statistics on these children are presented in Table 1, with the relevant variables being defined in Appendix 1.

By 1987 the EPI had achieved widespread coverage in Zambia, but it continued to expand through 1992. An on-going problem with the implementation, however, was the periodic non-availability of the vaccines due to transportation difficulties and shortages. When they were available however, the vaccines were given free of charge, and were reportedly seldomly refused when offered?

The following analysis is based on one of the central components of the EPI, the provision of the tetanus vaccine to pregnant women. Injection of tetanus toxoid is targeted towards reducing neonatal tetanus mortality, through the passage of maternal tetanus antibodies through the placenta to the fetus. Exact vaccine efficacy is not clearly established; two doses are typically recommended, although a single dose is still thought to provide significant protection to a newborn infant. Furthermore, booster vaccinations are usually recommended with each new pregnancy, as efficacy is much lower by the second year following the original shot.

Infants in Zambia are at considerable risk of neonatal tetanus. A nonsterile birth environment is the primary cause; this may include potentially infectious dressings on umbilical stumps by birth attendants. Onset of symptoms begins a few days following birth, and death usually occurs within 2-3 weeks. Case fatality rates tend to be high, especially when appropriate care is not available, as is the situation in much of Zambia. In a 1985 baseline survey, it was found that $\mathbf{0 . 4 3 \%}$ of newborn infants in Zambia died from neonatal tetanus, at a time when $62 \%$ of mothers were vaccinated (Zambia Ministry of Health, 1987). Thus just over $1 \%$ of the children of unvaccinated mothers died from neonatal tetanus.

During this period in Zambia, the tetanus vaccine was reportedly only available to pregnant women from "health professionals (doctors, nurses, and clinical officers)," and not administered through vertical campaigns. This is corroborated by the fact that over $98 \%$ of vaccinations reported in the data

\footnotetext{
${ }^{7}$ The institutional information in this section owes much to private communication with World Bank Senior Economist and Zambian Human Resources Task Manager Steen Jorgenson.
} 
were to women who also reported having visited a "health professional" for prenatal care.

\subsection{Evidence and Hypothesis Tests}

Focusing the analysis on tetanus has two important advantages. First, tetanus is not a contagious disease and, second, it is known from biomedical evidence that the direct effect of the vaccine should only be manifested through a mortality decrease in the first month of life. Such specific targeting of the benefits is uncommon among vaccinations. Any measurable impact of the tetanus vaccine above and beyond the direct effect of decreasing neonatal tetanus mortality will indicate that the vaccine acts also through the indirect pathways hypothesized in this paper. The null hypothesis is that the disease-specific effect of tetanus captures the vaccination's full mortality effect

$$
\frac{d S(t \mid x(p))}{d p_{k}}=\frac{d S_{k}\left(t \mid x_{k}(p)\right)}{d x_{k}} \frac{d x_{k}}{d p_{k}}\left(\prod_{j \neq k} S_{j}\right)
$$

The analysis in this section presents evidence rejecting the following three implications of this null hypothesis:

1. The biomedical effect of the tetanus vaccine should directly reduce the probability of neonatal mortality by about $1 \%$.

2. The tetanus vaccine should have no direct impact on post-neonatal mortality.

3. Birthweight should not be medically affected by the tetanus vaccine.

Implication 1 Figure 1 plots the Kaplan-Meier survival curve $S\left(t \mid x_{k}\right)$ for children age $0-24$ months, according to whether or not their mothers were vaccinated for tetanus while pregnant. Similarly, Table 2 Column 1 reports binary logit estimates of the probability of death in the first month of life.

The first important fact highlighted by the graph and table is that the tetanus effect on mortality is greater than $1 \%$. In fact it is about three times as large. Through the 1985 estimates of baseline prevalence, it is thought that this direct effect of vaccination on neonatal mortality in our survey period $1987-92$ should not exceed approximately $(.43 /(1-.62)=1.1) \%$. This is similar to the prevalence in other developing countries (Stroh, et al., 1987; Rodrigues, 1991). This "excess mortality" indicates that there may be other important 
effects of the vaccine intervention program, besides simply avoiding neonatal tetanus. However, because it is possible that this excess mortality is simply an artifact of mismeasurement of the actual tetanus incidence among the untreated population, it is important to examine more precise supporting evidence.

Implication 2 The second feature of Figure 1 is that the tetanus vaccine appears to continue to affect mortality even after the first month of life, when tetanus mortality becomes extremely rare. Table 2 Column 5 presents this same evidence estimated with a proportional hazard model for ages 1-6 months (ie. conditional on having survived the first month). It is seen that tetanus has a significant effect on the post-neonatal hazard of death. There could be numerous explanations for this association:

First, it could be that by easing the body's fight against tetanus, surviving infants are stronger and more easily ward off other mortality risks. However, the fact that most children with tetanus die suggests that reducing tetanus incidence will not change other causes of mortality through a disease interaction mechanism. Nutritional inputs may improve the ability to fight diarrhea, but a tetanus vaccine is unlikely to affect the health of surviving infants.

Nevertheless, the overall incidence of other fatal diseases may of course still change, since more infants are now able to survive the neonatal tetanus risk. However, this "replacement mortality" is usually hypothesized to arise from dependence in disease incidence, so that unobservable vulnerable people are more likely than others to get both tetanus and some other fatal disease, given that they survive tetanus once vaccinated. This would cause the survival curves to converge rather than diverge as they do in Figure 1.

Another potential explanation for the divergence is that obtaining a tetanus vaccination is correlated with obtaining other vaccinations once born, which could then cause a spurious effect of tetanus on post-neonatal mortality. However, in the first six months of life examined here, other vaccine preventable diseases are not yet significant mortality causes. Measles is the most prevalent and deadly of the other diseases prevented by the EPI package, but most children continue to carry maternal immunity past six months of age.

However, it could be that the availability of other vaccines, as indicated by the availability of tetanus, induces extra well-child visits to the doctor to 
get the dpt, bcg, and polio vaccines in the first few months of life. These well- child visits could provide the mechanism for the mortality differences observed. The differences could of course also be caused by other unobserved changes in health inputs such as nutrition and other inputs at the household level. Unfortunately, data is not available on well-child visits which could be used to explore this possibility.

As final evidence for indirect effects of the tetanus vaccine on postneonatal mortality, we cite a study from Burma (Stroh, et al., 1987) of 2 similar areas, in one of which the EPI was implemented earlier than the other. The study reported that indeed the tetanus vaccine was efficacious in reducing neonatal tetanus death. Although not highlighted, it can also be learned from the study that "in the non-EPI area the post-neonatal mortality rate was approximately three times higher than in the EPI area, " with $p$ i .10 significance.

Implication 3 To provide further evidence of indirect mortality effects of the tetanus intervention, Table 3 Column 1 presents a binary logit of whether an infant was born with low birthweight, and it is seen that again tetanus had a significant effect on improving birthweight. There is no medical pathway through which this effect would operate, which provides strong evidence that women who get the tetanus shot also invest in other inputs. Because it is well established medically that birthweight is an important determinant of child health and survival, this suggests an indirect pathway through which tetanus effects mortality.

\subsection{Controlling for Heterogeneity through Fixed Ef- fects Estimation}

There are still numerous potentially confounding variables which should be controlled for, as there could well be unobserved correlations between the health and mortality environment, and the probability of getting the tetanus vaccine. Households already investing in other inputs may be the ones most likely to invest in tetanus also, when the vaccine becomes available. Rosenzweig and Schultz (1983) propose an instrumental variables solution to this problem of heterogeneity biasing health input effects on birthweight. However, no valid instruments appear to be available in the Zambian DHS; 
instead, the large family and household sizes are exploited here to use fixed effects techniques to purge the error term of this heterogeneity.

To discuss this more concretely, let $H_{i}$ denote an individual's health outcome, $T_{i}$ tetanus treatment, $X_{i}$ a vector of exogenous socioeconomic characteristics, $\lambda_{h}$ unobserved household characteristics, $\nu_{m}$ unobserved mother's characteristics, and $\varepsilon_{i}$ a random disturbance. Then:

$$
H_{i}=\beta T_{i}+\gamma X_{i}+\lambda_{h}+\nu_{m}+\varepsilon_{i}
$$

Within Household If $\operatorname{cov}\left(T_{i}, \lambda_{h}\right) \neq 0$, then the estimated treatment effect $\beta$ will be biased. However, fixed effects estimation of the difference in health outcomes between two children in the same household will purge the error term of that correlation:

$$
\left(H_{2}-H_{1}\right)=\beta\left(T_{2}-T_{1}\right)+\gamma\left(X_{2}-X_{1}\right)+\left(\nu_{m 2}-\nu_{m 1}\right)+\left(\varepsilon_{2}-\varepsilon_{1}\right)
$$

Because the health outcome of low birthweight is measured as a binary variable in this case, the estimation is complicated somewhat; Neyman and Scott (1948) showed that nonlinear estimates would be inconsistent if there were only a few observations in the "short" dimension of the panel. Chamberlain (1980) presents a consistent conditional fixed effects logit estimator for qualitative outcomes which circumvents this problem. However, it is tractable only if the short dimension of the panel is not large; in the Zambian data, the average household contains approximately 20 children. Because of this, in Table 3 Column 3 a linear probability model (LPM) is instead presented, for which each of the incidental household intercept dummies was estimated (with 20 observations per household, this should be reasonably consistent).

The standard errors have not been corrected for heteroscedasticity, but by looking at the LPM in Table 3 Column 2 of the undifferenced analog to the low birthweight logit in column 1, it is seen that the uncorrected LPM estimates do not differ much from the logit ones.

This household fixed effects estimate indicates that tetanus vaccination is still a strong determinant of birthweight. It does not appear that the undifferenced estimates were biased by unmeasured household variables, such as regional tetanus availability, the health environment, access to medical care in the area, family perceptions of "normal" birthweight, etc. To further 
show this robustness to household fixed effects, Table 2 Column 3 also shows a within household fixed effects estimate of the probability of neonatal death, and the results are also virtually identical to the logit of neonatal mortality in Table 2 Column $1^{8}$.

Sibling Fixed Effects Although the results of the within household estimation are important, there could still be a confounding effect if $\operatorname{cov}\left(T_{i}, \nu_{m}\right) \neq$ 0 . This could arise if different mothers within the same household had different preferences or knowledge regarding tetanus vaccination. To investigate this possibility, Chamberlain fixed effects logit models were estimated using the most recent two children of all mothers who reported at least two births in the previous 5 years. Summary statistics for this siblings sample are reported in Table 1 Column 2. Because the Chamberlain procedure conditions on the sufficient statistic of the two siblings having different birthweight outcomes, the estimation only uses 338 mothers. Nevertheless, tetanus vaccination is still a significant negative covariate of low birthweight (Table 4 Column 1) and neonatal death (Table 2 Column 4). Furthermore, the marginal effects on these probabilies are even larger than in the within household and undifferenced estimates.

Other Potential Confounders It does not appear that the estimated effect of tetanus on birthweight is spurious due to the mothers who demand tetanus also being prone to use other unobservable inputs. However, it could be that in addition to the EPI intervention, the health system was being improved at the same time, and this was inducing more women to seek prenatal care (other than just tetanus vaccination), which could be affecting birthweight. This is unlikely given the cuts in the national health budget during this period (World Bank, 1994), which only the EPI was able to escape due to its external donor funding.

Nevertheless, we attempt to control for this, through within household (Table 3 Column 4) and within mother (Table 4 Column 2) estimates of low birthweight which include prenatal care as a covariate. The results show no particular effect on the tetanus coefficient when controlling for prenatal care.

${ }^{8}$ Again, the uncorrected $t$-statistics of the LPM in Table 2 Column 2 are virtually identical to the analogous logit $t$-statistics in Table 2 Column 1. 
A slightly different version of the same control is to restrict the sample to only those children whose mothers had received prenatal care. The low birthweight household fixed effects results are presented in Table 5 Column 1 (means for this sample are given in Table 1 Column 3), and the sibling fixed effects in Table 5 Column 3 (means are in Table 1 Column 4). Over $90 \%$ of the sample received prenatal care, and dropping the few who did not again has little effect on the tetanus coefficient. Of course if prenatal care is correlated with any remaining unobservables in the fixed effects error term then these tests will be inconsistent, but it is notable that the tests show litle effects.

These last tests are especially important given that few women refuse vaccinations in Zambia when offered. Conditional on having a prenatal visit, it may thus be interpreted that women who did not get the tetanus vaccination missed it because of non-availability. Controlling for regional availability through within household fixed effects means that tetanus vaccination may reasonably be interpreted as uncorrelated with the error term ${ }^{9}$. Rosenzweig and Wolpin (1988) have argued that even sibling fixed-effects may not be sufficient to purge input heterogeneity if parents respond to differences between their children. However, because the children are not yet born at the time that the inputs are being made, that is an unlikely source of bias here.

One final potential confounder which is addressed is that the onset of the economic crisis in an area could have affected both vaccine availability, and other unobservables which impact birthweight such as food consumption. This time-varying effect would not be compensated for simply by the fixed effects estimation. It is not clear how the crisis would have affected vaccine availability, because of the external funding, and also because tetanus toxoid is very heat stable and does not require maintenance of the cold chain to retain its efficacy. Nevertheless, we investigate the possibility, indirectly. This is done by noting that if for example transportation problems cause correlations between both food availability and vaccine availability, then this should also be evident seasonally. Outlying areas can be especially difficult to reach during the rainy season, and it would be expected then that dummies for the month of birth would capture some of this correlation due to "lean

\footnotetext{
${ }^{9} \mathrm{O}$ course, there may still be a bias if certain women repeated prenatal visits to increase the probability of finding the vaccine in stock, but this characteristic should be controlled for by the sibling fixed effects estimation
} 
times." Table 3 Column 5 presents within household fixed effects estimates controlling for month and year of birth; estimates for just those having received prenatal care are in Table 5 Column 2 (controlling for month and year of birth). Again, the estimated tetanus effect on birthweight is virtually unchanged. This further corroborates the evidence that although tetanus does not medically effect birthweight, its availability can significantly change health input mixes, and thus affect mortality through pathways other than avoidance of neonatal tetanus.

\section{Conclusion}

In this paper we have argued theoretically and empirically, that the typical evaluation of a disease-specific health policy is likely to be biased. The main reason is that a particular health policy not only changes the probability of death directly, but it also changes the incentives to invest in other cause of death as well as to increase the overall spending on health.

The empirical evidence presented above certainly suggests the presence of indirect effects of the EPI intervention on mortality, in addition to lowering cause-specific deaths. If the tetanus vaccine simply avoided tetanus death, then it should cause a $1 \%$ decrease in mortality; however, the effect measured here is significantly larger. Furthermore, we also observe that the response to tetanus vaccination is a superior birthweight and a lower probability of death six months down the road, phenomena for which there is no direct medical pathway. It is likely that when tetanus becomes available, this signals the more general availability of the whole EPI package, which could significantly increase a child's ability to survive numerous deadly childhood diseases. Women know that infants are more likely to live longer, and are thus willing to invest in other (unobserved) inputs such as nutrition, and care for themselves during pregnancy. These are important effects of the EPI intervention program, and should be measured more carefully. The overall cost-effectiveness estimates of an intervention may well differ depending on whether the indirect effects are taken into account. 


\section{References}

[1] Arthur, W., (1981), 'The Economics of Risks to Life', AER, v 71, 54-64.

[2] Becker, G., and C., Mulligan, (1994), 'A Theory of Optimal Discounting', Working Paper, Center for The Study of The Economy and The State, University of Chicago.

[3] Chamberlain, G. (1980) 'Analysis of Covariance with Qualitative Data', Review of Economic Studies 47:225.

[4] Geoffard, P., and Philipson, T., (1994), 'Disease Eradication: Public vs Private Vaccination', Working Paper, Department of Economics, University of Chicago.

[5] Grossman, M., (1972), 'On the Concept of Health Capital and The Demand for Health', Journal of Political Economy, , v 80, 223-50.

[6] Kenkel, D., G.,Tolley, and R., Fabian (Eds), Valuing Health for Policy: An Economic Approach, Chicago: University of Chicago Press.

[7] Neyman, J. and E. Scott (1948) 'Consistent Estimates Based on Partially Consistent Observations', Econometrica 16:1.

[8] Philipson, T., (1994), 'Welfare Loss of Diseases and The Theory of Taxation', forthcoming, Journal of Health Economics.

[9] Rodrigues, L. 'EPI Target diseases: Measles, Tetanus, Polio, TB, Pertussis, and Diphtheria', in R. Feachem and D. Jamison (eds.) Disease and Mortality in Sub-Saharan Africa, Washington, DC: World Bank.

[10] Rosen, S., (1988), 'The Value of Changes in Life Expectancy', Journal of Risk and Uncertainty, 1, 285-304.

[11] Rosen, S., (1994), 'The Quantity and Quality of Life: A Conceptual Framework' in Kenkel, D., G.,Tolley, and R., Fabian (Eds), Valuing Health for Policy: An Economic Approach, Chicago: University of Chicago Press. 
[12] Rosenzweig, M.,and T.P., Schultz, (1983),'Estimation a Health Production Functions; Heterogeneity, The Demand for Helath Inputs, and Their Effects on Birthweight', Journal of Political Economy, v 91, 723-43.

[13] Rosenzweig, M.,and K., Wolpin (1988) 'Heterogeneity, Intrafamily Distribution and Child Health', Journal of Human Resources 23(4):437.

[14] Stroh, G., et al. (1987) 'Measurement of Mortality from Neonatal Tetanus in Burma', Bulletin of the WHO, 65(3):309.

[15] United Nations, (1994), Report of The Executive Director, Economic and Social Council, New York.

[16] Viscusi, K., (1992), Fatal Tradeoffs : Public and Private Responsibilities for Risk, New York: Oxford University Press.

[17] World Bank, (1993), Investing in Health, World Bank Development Report, Oxford University Press.

[18] World Bank, (1994) Zambia Poverty Assessment, Human Resources Division, Southern Africa Department, Africa Regional Office.

[19] Zambia, Ministry of Health (1987) CDD/EPI Baseline Survey Report. 


\section{APPENDIX 1: Variable Definitions}

\begin{tabular}{|c|c|}
\hline Neonatal Death & $=1$ if child died in the first month of life \\
\hline Tetanus & $=1$ if mother vaccinated for tetanus while pregnant \\
\hline Prenatal & $=1$ if mother had modern prenatal care while pregnant \\
\hline Low Birthweight & $\begin{array}{l}=1 \text { if mother reports that child was smaller than average } \\
\text { or very small at birth }\end{array}$ \\
\hline Mother's Age & $=$ Mother's age at birth of child \\
\hline First Born & $=1$ if child was the mother's first \\
\hline High Parity & $=$ Parity if child was more than 10th delivered by mother \\
\hline Illiterate & $=1$ if mother cannot read a letter or newspaper \\
\hline High Education & $=1$ if mother received post-secondary education \\
\hline Rural & $=1$ if mother resides in a rural area \\
\hline
\end{tabular}


TABLE 1: Descriptive Statistics: Means (s.d. in parentheses)

\begin{tabular}{|c|c|c|c|c|}
\hline & (1) & $(2)$ & $(\overline{3)}$ & $(4)$ \\
\hline Neonatal Death & $\begin{array}{l}.04 \\
(.20)\end{array}$ & $\begin{array}{l}.04 \\
(.20)\end{array}$ & $\begin{array}{l}.04 \\
(.19)\end{array}$ & $\begin{array}{l}.04 \\
(.19)\end{array}$ \\
\hline Tetanus & $\begin{array}{l}.81 \\
(.39)\end{array}$ & $\begin{array}{l}.81 \\
(.39)\end{array}$ & $\begin{array}{l}.87 \\
(.34)\end{array}$ & $\begin{array}{l}.87 \\
(.34)\end{array}$ \\
\hline Prenatal & $\begin{array}{l}.91 \\
(.28)\end{array}$ & $\begin{array}{l}.92 \\
(.28)\end{array}$ & - & - \\
\hline Mother's Age & $\begin{array}{l}28 \\
(7.1)\end{array}$ & $\begin{array}{l}28 \\
(6.4)\end{array}$ & $\begin{array}{l}28 \\
(7.0)\end{array}$ & $\begin{array}{l}28 \\
(6.4)\end{array}$ \\
\hline Low Birthweight & $\begin{array}{l}.12 \\
(.32)\end{array}$ & $\begin{array}{l}.12 \\
(.32)\end{array}$ & $\begin{array}{l}.12 \\
(.32)\end{array}$ & $\begin{array}{l}.12 \\
(.32)\end{array}$ \\
\hline First Born & $\begin{array}{l}.22 \\
(.42)\end{array}$ & $\begin{array}{l}.11 \\
(.31)\end{array}$ & $\begin{array}{l}.22 \\
(.42)\end{array}$ & $\begin{array}{l}.11 \\
(.31)\end{array}$ \\
\hline High Parity & $\begin{array}{l}.12 \\
(1.23)\end{array}$ & $\begin{array}{l}.12 \\
(1.23)\end{array}$ & $\begin{array}{l}.12 \\
(1.21)\end{array}$ & $\begin{array}{l}.11 \\
(1.19)\end{array}$ \\
\hline Illiterate & $\begin{array}{l}.37 \\
(.48)\end{array}$ & $\begin{array}{l}.38 \\
(.49)\end{array}$ & $\begin{array}{l}.34 \\
(.47)\end{array}$ & $\begin{array}{l}.35 \\
(.48)\end{array}$ \\
\hline High Education & $\begin{array}{l}.02 \\
(.12)\end{array}$ & $\begin{array}{l}.01 \\
(.12)\end{array}$ & $\begin{array}{l}.02 \\
(.13)\end{array}$ & $\begin{array}{l}.02 \\
(.12)\end{array}$ \\
\hline Rural & $\begin{array}{l}.57 \\
(.49)\end{array}$ & $\begin{array}{l}.59 \\
(.49)\end{array}$ & $\begin{array}{l}.54 \\
(.50)\end{array}$ & $\begin{array}{l}.55 \\
(.50)\end{array}$ \\
\hline Sample Size & 6509 & 4174 & 5955 & 3825 \\
\hline
\end{tabular}


Table 1 Column Descriptions:

(1) All children, up to the 3 most recent born by each mother since 1987.

(2) Most recent 2 children; latest child only included if had an earlier sibling in this sample since 1987.

(3) All children (as in (1)), but only if mother received modern prenatal care while pregnant.

(4) Most recent 2 children with siblings (as in (2)), but only if mother received prenatal care (as in (3)). 
TABLE 2: Probability of Neonatal and Post-neonatal Death ${ }^{1,2}$

\begin{tabular}{|c|c|c|c|c|c|}
\hline & (1) & $\overline{(2)}$ & $(\mathbf{3})$ & $(4)$ & $(5)$ \\
\hline Tetanus & $\begin{array}{l}-.029^{* *} \\
(5.27)\end{array}$ & $\begin{array}{l}-.036 * * \\
(5.53)\end{array}$ & $\begin{array}{l}-.034^{* *} \\
(5.08)\end{array}$ & $\begin{array}{l}-.041^{* *} \\
(2.36)\end{array}$ & $\begin{array}{l}-. .353^{* *} \\
(2.21)\end{array}$ \\
\hline Prenatal & - & - & - & - & - \\
\hline Mother's Age & $\begin{array}{l}-.003 \\
(1.00)\end{array}$ & $\begin{array}{l}-.003 \\
(1.04)\end{array}$ & $\begin{array}{l}-.002 \\
(.52)\end{array}$ & - & $\begin{array}{r}-.000 \\
(.00)\end{array}$ \\
\hline (Mother's Age) $^{2}$ & $\begin{array}{l}.000 \\
(.82)\end{array}$ & $\begin{array}{l}.000 \\
(.88)\end{array}$ & $\begin{array}{l}.000 \\
(.38)\end{array}$ & - & $\begin{array}{l}-.000 \\
(.24)\end{array}$ \\
\hline First Born & $\begin{array}{l}.010 \\
(1.41)\end{array}$ & $\begin{array}{l}.012 \\
(1.49)\end{array}$ & $\begin{array}{l}.013 \\
(1.57)\end{array}$ & - & $\begin{array}{r}-.002 \\
(.01)\end{array}$ \\
\hline High Parity & $\begin{array}{l}.001 \\
(.31)\end{array}$ & $\begin{array}{l}.001 \\
(.27)\end{array}$ & $\begin{array}{l}.001 \\
(.39)\end{array}$ & - & $\begin{array}{r}-.043 \\
(.51)\end{array}$ \\
\hline Iliterate & $\begin{array}{l}.008 \\
(1.44)\end{array}$ & $\begin{array}{l}.008 \\
(1.51)\end{array}$ & $\begin{array}{l}.011^{* *} \\
(2.07)\end{array}$ & - & $\begin{array}{l}.221 \\
(1.49)\end{array}$ \\
\hline High Education & $\begin{array}{r}-.003 \\
(.12)\end{array}$ & $\begin{array}{r}-.002 \\
(.08)\end{array}$ & $\begin{array}{l}-.006 \\
(.27)\end{array}$ & - & $\begin{array}{l}.144^{* *} \\
(2.45)\end{array}$ \\
\hline Rural & $\begin{array}{l}.008 \\
(1.48)\end{array}$ & $\begin{array}{l}.008 \\
(1.44)\end{array}$ & - & - & $\begin{array}{l}.219 \\
(1.44)\end{array}$ \\
\hline Constant & $\begin{array}{l}-.065 \\
(1.44)\end{array}$ & $\begin{array}{l}.115 \\
(2.41)\end{array}$ & $\begin{array}{l}.13 \\
(2.32)\end{array}$ & - & - \\
\hline Household Dummies & No & No & Yes & No & No \\
\hline Mother Dummies & No & No & No & Yes & No \\
\hline Year Dummies & No & No & Yes & Yes & No \\
\hline Month Dummies & No & No & Yes & No & No \\
\hline Number of obs & 6509 & 6509 & 6509 & 149 & $\mathbf{5 3 7 7}$ \\
\hline
\end{tabular}

\footnotetext{
${ }^{1}$ Marginal Effects (and t-statistics) are reported for all Logit models in Tables $2-5$ [transformed by muliplying coefficient by $P(1-p)]$.

$2 *, * 4$ denote significance at 90 th and 95 th percentiles, respectively.
} 
Table 2 Regression Descriptions:

(1) Logit of the probability of neonatal death, full sample used.

(2) Linear Probability Model (LPM) of the probability of neonatal death, full sample used (t-statistics have not been corrected for heteroscedasticity).

(3) LPM Prob(Neonatal Death), within household fixed effects, full sample; month and year dummies included.

(4) Chamberlain Conditional Logit Prob(Neonatal Death), within mother fixed effects (most recent 2 children only)

(5) Proportional hazard model of Prob(Death | Survival to Age $t, t=1 . . .6$ months); sample is conditioned to contain only those who survive to 1 st month, and who were not censored. Raw coefficients reported (not marginal effects). 
TABLE 3: Probability of Low Birthweight

\begin{tabular}{|c|c|c|c|c|c|}
\hline & (1) & $(2)$ & (3) & (4) & $(5)$ \\
\hline Tetanus & $\begin{array}{l}-.030^{*} \\
(3.02)\end{array}$ & $\begin{array}{l}-.032^{* *} \\
(\mathbf{3 . 0 4})\end{array}$ & $\begin{array}{l}-.035^{* *} \\
(3.29)\end{array}$ & $\begin{array}{l}-.037^{* *} \\
(3.11)\end{array}$ & $\begin{array}{l}-.038^{* *} \\
(3.13)\end{array}$ \\
\hline Prenatal & - & - & - & $\begin{array}{l}.008 \\
(.47)\end{array}$ & $\begin{array}{l}.009 \\
(.55)\end{array}$ \\
\hline Mother's Age & $\begin{array}{l}-.005 \\
(1.05)\end{array}$ & $\begin{array}{l}-.006 \\
(1.23)\end{array}$ & $\begin{array}{l}-.008 \\
(1.49)\end{array}$ & $\begin{array}{l}-.008 \\
(1.50)\end{array}$ & $\begin{array}{l}-.007 \\
(1.36)\end{array}$ \\
\hline (Mother's Age) $^{2}$ & $\begin{array}{l}.000 \\
(.64)\end{array}$ & $\begin{array}{l}.000 \\
(.85)\end{array}$ & $\begin{array}{l}.000 \\
(1.25)\end{array}$ & $\begin{array}{l}.000 \\
(1.25)\end{array}$ & $\begin{array}{l}.000 \\
(1.14)\end{array}$ \\
\hline First Born & $\begin{array}{l}.039 * * \\
(3.24)\end{array}$ & $\begin{array}{l}.044^{* *} \\
(3.52)\end{array}$ & $\begin{array}{l}.046^{* *} \\
(3.64)\end{array}$ & $\begin{array}{l}.046^{* *} \\
(3.64)\end{array}$ & $\begin{array}{l}.049^{* *} \\
(3.74)\end{array}$ \\
\hline High Parity & $\begin{array}{l}.006^{* *} \\
(2.08)\end{array}$ & $\begin{array}{l}.007^{*} \\
(1.92)\end{array}$ & $\begin{array}{l}.007^{*} \\
(1.89)\end{array}$ & $\begin{array}{l}.007^{*} \\
(1.89)\end{array}$ & $\begin{array}{l}.006^{*} \\
(1.84)\end{array}$ \\
\hline Illiterate & $\begin{array}{r}-.002 \\
(.17)\end{array}$ & $\begin{array}{r}-.001 \\
(.16)\end{array}$ & $\begin{array}{r}-.001 \\
(.12)\end{array}$ & $\begin{array}{l}-.001 \\
(.06)\end{array}$ & $\begin{array}{r}-.001 \\
(.09)\end{array}$ \\
\hline High Education & $\begin{array}{l}.024 \\
(.75)\end{array}$ & $\begin{array}{l}.023 \\
(.72)\end{array}$ & $\begin{array}{l}.004 \\
(.11)\end{array}$ & $\begin{array}{l}.003 \\
(.10)\end{array}$ & $\begin{array}{l}.000 \\
(.01)\end{array}$ \\
\hline Rural & $\begin{array}{l}.010 \\
(1.09)\end{array}$ & $\begin{array}{l}.009 \\
(1.08)\end{array}$ & - & - & - \\
\hline Constant & $\begin{array}{l}-.102 \\
(1.33)\end{array}$ & $\begin{array}{l}.242 \\
(3.15)\end{array}$ & $\begin{array}{l}.263 \\
(3.13)\end{array}$ & $\begin{array}{l}.258 \\
(3.05)\end{array}$ & $\begin{array}{l}.243 \\
(2.73)\end{array}$ \\
\hline $\begin{array}{l}\text { Household Dummies } \\
\text { Mother Dummies } \\
\text { Year Dummies } \\
\text { Month Dummies }\end{array}$ & $\begin{array}{l}\text { No } \\
\text { No } \\
\text { No } \\
\text { No }\end{array}$ & $\begin{array}{l}\text { No } \\
\text { No } \\
\text { No } \\
\text { No }\end{array}$ & $\begin{array}{l}\text { Yes } \\
\text { No } \\
\text { No } \\
\text { No }\end{array}$ & $\begin{array}{l}\text { Yes } \\
\text { No } \\
\text { No } \\
\text { No }\end{array}$ & $\begin{array}{l}\text { Yes } \\
\text { No } \\
\text { Yes } \\
\text { Yes }\end{array}$ \\
\hline Number of obs & 6509 & 6509 & 6509 & 6509 & 6509 \\
\hline
\end{tabular}


Table 3 Regression Descriptions:

(1) Logit Prob(Low Birthweight), full sample.

(2) LPM Prob(Low Birthweight), full sample.

(3) LPM Prob(Low Birthweight), within household fixed effects; full sample.

(4) LPM Prob(Low Birthweight), within household fixed effects; full sample, with Prenatal covariate.

(5) LPM Prob(Low Birthweight), within household fixed effects; full sample, with month and year dummies, and prenatal covariate. 
TABLE 4: Mother Fixed Effects, Probability of Low Birthweight

\begin{tabular}{lll}
\hline \hline & $(1)$ & $(2)$ \\
\cline { 2 - 3 } Tetanus & $-.055^{* *}$ & $-.049^{*}$ \\
& $(2.13)$ & $(1.77)$ \\
Prenatal & - & -.035 \\
& & $(.64)$ \\
Mother's Age & - & - \\
(Mother's Age) & - & - \\
First Born & & \\
High Parity & - & - \\
Illiterate & - & - \\
High Education & - & - \\
Rural & - & - \\
Constant & - & - \\
& & \\
Household Dummies & No & No \\
Mother Dummies & Yes & Yes \\
Year Dummies & Yes & Yes \\
Month Dummies & No & No \\
Number of obs & $\mathbf{3 3 8}$ & $\mathbf{3 3 8}$ \\
\hline \hline
\end{tabular}

Table 4 Regression Descriptions:

(1) Chamberlain Conditional Logit Prob(Low Birthweight), within mother fixed effects (most recent 2 children only).

(2) As in (1), but also includes prenatal covariate. 
TABLE 5: Probability of Low Birthweight if had Prenatal Care

\begin{tabular}{|c|c|c|c|}
\hline & $(1)$ & $(2)$ & (3) \\
\hline Tetanus & $\begin{array}{l}-.039^{* *} \\
(3.11)\end{array}$ & $\begin{array}{l}-.039^{* *} \\
(3.10)\end{array}$ & $\begin{array}{l}-.055^{*} \\
(1.82)\end{array}$ \\
\hline Prenatal & - & - & - \\
\hline Mother's Age & $\begin{array}{l}-.002 \\
(.44)\end{array}$ & $\begin{array}{l}-.002 \\
(.44)\end{array}$ & - \\
\hline (Mother's Age) $^{2}$ & $\begin{array}{l}.000 \\
(.15)\end{array}$ & $\begin{array}{l}.000 \\
(.16)\end{array}$ & - \\
\hline First Born & $\begin{array}{l}.055^{* *} \\
(4.16)\end{array}$ & $\begin{array}{l}.056^{* *} \\
(4.12)\end{array}$ & - \\
\hline High Parity & $\begin{array}{l}.010^{* *} \\
(2.61)\end{array}$ & $\begin{array}{l}.010^{* *} \\
(2.59)\end{array}$ & - \\
\hline Illiterate & $\begin{array}{r}-.002 \\
(.27)\end{array}$ & $\begin{array}{r}-.003 \\
(.28)\end{array}$ & - \\
\hline High Education & $\begin{array}{l}-.003 \\
(.09)\end{array}$ & $\begin{array}{r}-.006 \\
(.17)\end{array}$ & - \\
\hline Rural & - & - & - \\
\hline Constant & $\begin{array}{l}.166 \\
(1.86)\end{array}$ & $\begin{array}{l}.167 \\
(1.78)\end{array}$ & $\begin{array}{l}.001 \\
(.01)\end{array}$ \\
\hline $\begin{array}{l}\text { Household Dummies } \\
\text { Mother Dummies } \\
\text { Year Dummies } \\
\text { Month Dummies }\end{array}$ & $\begin{array}{l}\text { Yes } \\
\text { No } \\
\text { No } \\
\text { No }\end{array}$ & $\begin{array}{l}\text { Yes } \\
\text { No } \\
\text { Yes } \\
\text { Yes }\end{array}$ & $\begin{array}{l}\text { No } \\
\text { Yes } \\
\text { Yes } \\
\text { No }\end{array}$ \\
\hline Number of obs & 5955 & $\mathbf{5 9 5 5}$ & 296 \\
\hline
\end{tabular}


Table 5 Regression Descriptions:

(1) LPM Prob(Low Birthweight), within household fixed effects; only for households in which all mothers received prenatal care.

(2) As in (1), but includes month, year dummies.

(3) Chamberlain Conditional Logit Prob(Low Birthweight), within mother fixed effects (most recent 2 children only). 


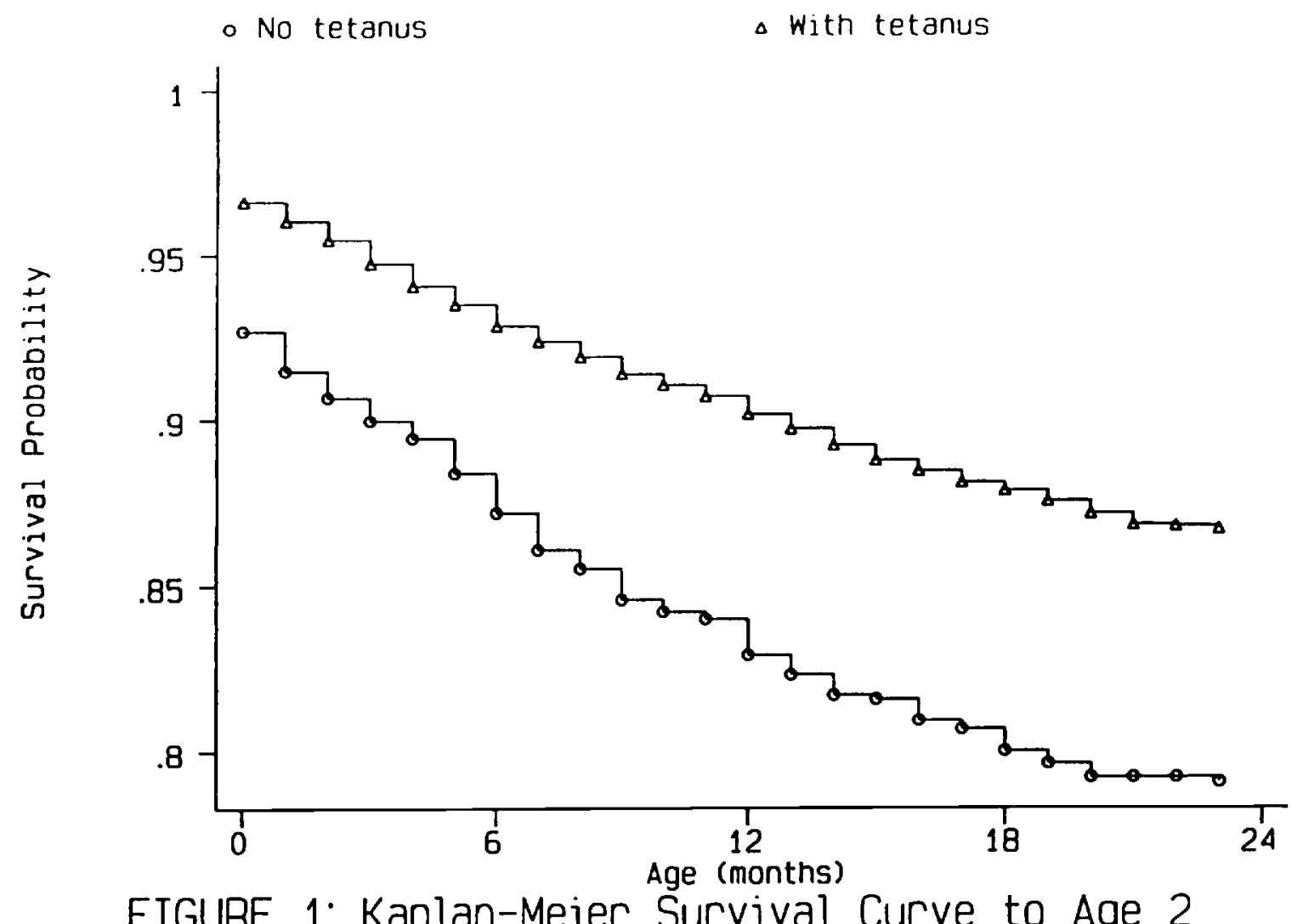

FIGURE 1: Kaplan-Meier Survival Curve to Age 2 